12

\title{
Темплатный синтез монодисперсных углеродных наноточек
}

\author{
() Д.А. Курдюков ${ }^{1}$, Д.А. Еуров ${ }^{1,2}$, Е.Ю. Стовпяга ${ }^{1}$, Д.А. Кириленко ${ }^{1}$, С.В. Коняхин ${ }^{1,3}$, \\ А.В. Швидченко ${ }^{1}$, В.Г. Голубев ${ }^{1}$ \\ ${ }^{1}$ Физико-технический институт им. А.Ф. Иофффе РАН, \\ Санкт-Петербург, Россия \\ ${ }^{2}$ Санкт-Петербургский национальный исследовательский университет \\ информационных технологий, механики и оптики, \\ Санкт-Петербург, Россия \\ ${ }^{3}$ Санкт-Петербургский национальный исследовательский академический университет РАН, \\ Санкт-Петербург, Россия \\ E-mail: kurd@gvg.ioffe.ru
}

(Поступила в Редакцию 17 мая 2016 г.)

\begin{abstract}
Методом темплатного синтеза получены монодисперсные углеродные наноточки в порах мезопористых частиц кремнезема. Метод основан на введении в поры прекурсора (органосилана), его терморазложении с образованием углеродных наноточек и последующем удалении темплата. Проведены структурные исследования наноматериала и показано, что углеродные наноточки имеют форму, близкую к сферической, и обладают графитоподобной структурой. По данным динамического светорассеяния размер углеродных наноточек составляет $3.3 \pm 0.9 \mathrm{~nm}$.
\end{abstract}

Д.А. Еуров, Д.А. Курдюков и Е.Ю. Стовпяга благодарят за финансовую поддержку РФФИ (грант № 16-03-00472).

В последние годы углеродные наноточки (УНТ) благодаря своим уникальным свойствам начали широко использоваться в различных областях техники и медицины. По сравнению с традиционными полупроводниковыми квантовыми точками и органическими красителями люминесцентные УНТ обладают рядом преимуществ: высокой растворимостью в воде, химической инертностью, фотостабильностью [1-4]. Биосовместимость и малая токсичность УНТ обусловливают их применение в качестве маркеров, биосенсоров и систем доставки лекарств [3,5-7]. Особенности электронной структуры функционализированных УНТ, являющихся и донорами $[1,8]$, и акцепторами $[1,4]$, а также наличие электрохимической люминесценции [1,2], позволяют использовать УНТ в оптронике $[1,3,9]$, сенсорах $[3,9,10]$ и катализе $[3,9,11]$.

К настоящему времени развиты физические (дуговой разряд $[1,2]$, лазерная абляция [1-3], микроволновое облучение [2], сольвотермальная обработка [2]) и химические (электрохимическая карбонизация [1-3], терморазложение/горение [1], синтез в растворах [3]) методы получения УНТ. В качестве прекурсоров для синтеза УНТ используются природный газ [1], углеводы [1,2,7], графен и другие аллотропные формы углерода [3], а также экзотические материалы, такие как алоэ [10], апельсиновый сок [12] и пищевые отходы [13]. Углеродные наноточки, синтезируемые этими методами, являются полидисперсными. Для очистки и уменьшения разброса размеров УНТ применяются диализ, хроматография, электрофорез, центрифугирование и другие методы $[1,2]$. Для получения УНТ с более низкой дисперсией размеров их синтез проводится на поверхности носителя (мо- дифицированных триблок-сополимером частиц кремнезема [14]) или в порах матриц (синтетических цеолитов $\mathrm{NaY}[15]$ и пористого кремнезема [16]).

Недавно [17,18] нами был разработан метод быстрого синтеза субмикронных монодисперсных сферических мезопористых частиц кремнезема (МСМЧК) посредством контролируемой коагуляции нанометровых кластеров $\mathrm{SiO}_{2}$-цетилтриметиламмоний бромид (ЦТАБ), состоящих из трубок аморфного $\mathrm{SiO}_{2}$. Важными достоинствами МСМЧК являются наличие внутренней системы цилиндрических наноканалов одинакового диаметpa (контролируемо варьируемого в пределах 2-5 nm) объемом до $60 \%$ от объема частицы и низкое среднеквадратичное отклонение диаметров частиц (менее 10\%) [17-19]. Разработаны методы синтеза в мезопорах наночастиц оксидов [20,21] и металлов [22,23]. МСМЧК вполне подходят в качестве темплатов и для синтеза УНТ. Одинаковые размер и форма МСМЧК обеспечат одинаковые условия протекания реакции синтеза УНТ во всех частицах, монодисперсные мезопоры позволят получить углеродные наноточки строго заданного размера.

Настоящая работа посвящена разработке метода синтеза УНТ посредством термического разложения прекурсора - аминопропилтриэтоксисилана (АПТЭС) в порах МСМЧК диаметром $3.10 \pm 0.15 \mathrm{~nm}$ без осаждения массивного углеродного материала на внешнюю поверхность частиц. Метод обеспечивает близкое к полному однократное заполнение пор темплата прекурсором, содержащим 49 wt.\%. углерода, поэтому выход конечного продукта составляет до $100 \mathrm{mg}$ УНТ на $1 \mathrm{~g}$ темплата. Для растворения темплата применен 
однокомпонентный травитель, не загрязняющий УНТ. Графитоподобные наноточки являются монодисперсными, что обусловливается монодисперсностью диаметров мезопор.

МСМЧК синтезированы с использованием цетилтриметиламмоний бромида в качестве структурообразующего вещества. Синтез проведен методом гидролиза тетраэтоксисилана (ТЭОС) в ЦТАБ-этаноло-водно-аммиачной среде. Соотношение мольных концентраций исходных реагентов ТЭОС : ЦТАБ : $\mathrm{C}_{2} \mathrm{H}_{5} \mathrm{OH}: \mathrm{NH}_{3}: \mathrm{H}_{2} \mathrm{O}$ составило $1: 0.25: 250: 45: 400$ соответственно. Для удаления органических веществ синтезированные частицы были отожжены на воздухе при $550^{\circ} \mathrm{C}$. Диаметр мезопор в частицах равен $3.10 \pm 0.15 \mathrm{~nm}$, удельная поверхность и объем пор составили $850 \mathrm{~m}^{2} / \mathrm{g}$ и $0.6 \mathrm{~cm}^{3} / \mathrm{g}$ (58\%) соответственно, диаметр МСМЧК равен $720 \pm 50 \mathrm{~nm}$. Подробно методика синтеза частиц описана в работах $[17,18]$.

Углеродные наноточки синтезировались в мезопорах частиц следующим образом. Навеска МСМЧК массой $1 \mathrm{~g}$ помещалась в стеклянный бюкс. Затем в бюкс вливался $50 \mathrm{wt} . \%$ спиртовой раствор АПТЭС массой $1 \mathrm{~g}$. Бюкс закрывался крышкой, навеска МСМЧК находилась в контакте с раствором в течение $3 \mathrm{~h}$. При этом АПТЭС проникал в мезопоры, заполнение пор МСМЧК прекурсором приближалось к полному (механизм полного заполнения мезопор рассмотрен в работах [20,21]). Затем частицы высушивались при $50^{\circ} \mathrm{C}$ и отжигались на воздухе при $250^{\circ} \mathrm{C}$ в течение $5 \mathrm{~h}$. Для травления материала темплата (аморфного $\mathrm{SiO}_{2}$ ) навеску частиц помещали в $5 \mathrm{~g} 40 \mathrm{wt} \%$ HF. После растворения МСМЧК углеродные наноточки коагулировали, и в течение нескольких часов образовавшиеся агрегаты осаждались на дно сосуда. Затем осадок УНТ промывался деионизованной водой и редиспергировался под действием ультразвука. Выход конечного продукта составил $\sim 100 \mathrm{mg}$ УНТ на $1 \mathrm{~g}$ МСМЧК. Отметим, что разработанный метод синтеза не требует длительных и дорогостоящих процедур очистки УНТ, таких как, например, диализ [16]. Однокомпонентный состав прекурсора и травителя минимизирует содержание неконтролируемых примесей в синтезируемых УНТ.

Центрифугирование коллоидного раствора УНТ для очистки от агрегатов было проведено при помощи препаративной ультрацентрифуги Beckman Coulter Optima L-XP 100, снабженной ротором SW-60Ti. Время центрифугирования составляло $1 \mathrm{~h}$, скорость вращения ротоpa $11000 \mathrm{~min}^{-1}$ (ускорение на дне кюветы $15000 \mathrm{~g}$ ).

Размер УНТ регистрировался методом динамического светорассеяния (ДСР) на приборе Malvern Zetasizer Nano ZS при температуре $25^{\circ} \mathrm{C}$. Расчет распределения гидродинамических диаметров УНТ осуществлялся автоматически на основе анализа корреляционной функции флуктуаций интенсивности рассеянного света с помощью алгоритма мультимодального узкого распределения, имеющегося в программном обеспечении анализатора. Среднеквадратичное отклонение диаметров
УНТ принималось равным $W_{1 / 2} / 2.36$, где $W_{1 / 2}-$ значение ширины кривой распределения частиц по размерам на полувысоте, полученное с помощью встроенного программного обеспечения прибора.

Исследования микроструктуры частиц кремнезема, содержащих в порах УНТ, и индивидуальных УНТ после растворения темплата проводились на просвечивающем электронном микроскопе (ПЭМ) Jeol JEM-2100F. При приготовлении образца для микроскопии частицы наносились на поддерживающую пленку из ультратонкой графеновой бумаги. Измерение оптической плотности проведено на приборе ThermoScientific NanoDrop 2000c.

Органосилан АПТЭС был выбран в качестве прекурсора по следующим причинам. Как показали авторы [24,25], терморазложение смеси органосиланов с органическими кислотами при относительно невысоких температурах (до $250^{\circ} \mathrm{C}$ ) приводит к образованию функционализированных кремнием УНТ, имеющих квантовый выход фотолюминесценции до 47\% [24]. Благодаря высокому массовому содержанию углерода в АПТЭС (49wt.\%) и реализации близкого к полному заполнения пор МСМЧК прекурсором разработанный нами метод позволил достичь большого выхода конечного продукта.

Рассмотрим процессы, протекающие при синтезе УНТ в порах темплата. При длительном контакте МСМЧК с раствором АПТЭС последний практически полностью переходит из раствора внутрь частиц благодаря высокой адсорбционной способности поверхности мезопор [26,27]. Синтез УНТ обычно проводят в инертной атмосфере или в вакууме [1-3,26,27]. Пространство пор МСМЧК нанометровых размеров можно в определенных случаях рассматривать как безвоздушное, даже если процесс проводится на воздухе. Согласно [28,29], массоперенос в микропористых и мезопористых материалах происходит посредством диффузии в адсорбированном поверхностью пор слое молекул газа. Значения коэффициента диффузии различных газов в порах находятся в пределах $10^{-8}-10^{-7} \mathrm{~m}^{2} / \mathrm{s}$ [29]. Если в порах происходит деструкция вещества, сопровождающаяся большим газовыделением, диффузия молекул кислорода из атмосферы внутрь частиц будет затруднена вследствие движения молекул газообразных продуктов реакции наружу.

При термическом разложении этоксисиланов (как показано на примере ТЭОС в [30]) в инертной атмосфере образуются следующие газообразные продукты: ацетальдегид, этанол, этилен, метан, монооксид углерода, вода, водород. При разложении АПТЭС дополнительно образуются аммиак, пропилен, пропан, изобутилен [31]. Диффундируя в мезопорах, молекулы углеводородов (особенно непредельных), по-видимому, взаимодействуют друг с другом. В результате реакций полимеризации, поликонденсации и дегидрирования в мезопорах формируются углеродные нанокластеры. Монодисперсные УНТ, образовавшиеся в цилиндрических наноканалах (мезопорах внутри МСМЧК), схематически показаны на рис. 1. 


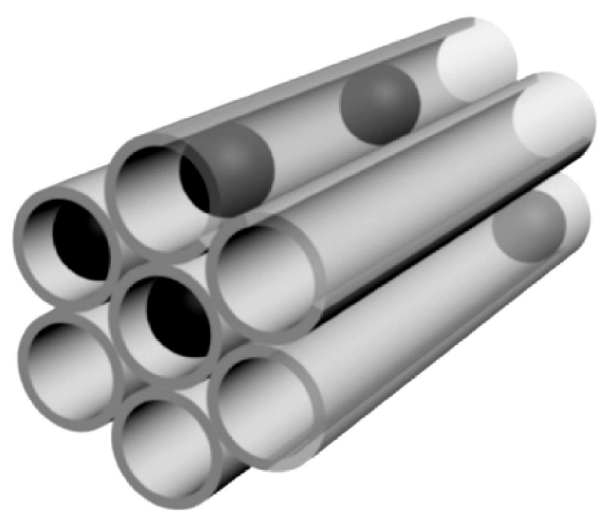

Рис. 1. Схематическое изображение углеродных наноточек в цилиндрических порах МСМЧК.

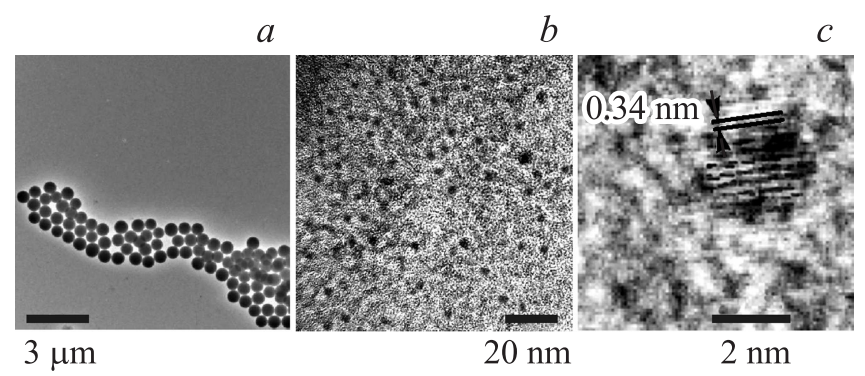

Рис. 2. Полученные методами ПЭМ $(a, b)$ и ПЭМВР $(c)$ изображения МСМЧК, содержащих в порах УНТ $(a)$ и УНТ после селективного травления материала МСМЧК $(b, c)$. Стрелки и линии на части $(c)$ обозначают характерное межплоскостное расстояние в УНТ.

Температура, при которой проводилось разложение АПТЭС $\left(250^{\circ} \mathrm{C}\right)$, относительно низкая. Так, по данным термогравиметрического анализа [32] терморазложение аминопропиловых групп, химически связанных с поверхностью мезопористого кремнезема типа SBA-15, происходит в диапазоне $400-600^{\circ} \mathrm{C}$. В нашем случае, во-первых, молекулы АПТЭС адсорбированы поверхностью мезопор, а не связаны с ней химически. Во-вторых, химически активные функциональные группы на поверхности пор [27] могут, вероятно, каталитически ускорять процессы разложения АПТЭС и формирования УНТ таким образом, что эти процессы протекают уже при $250^{\circ} \mathrm{C}$. Ранее [27] мы показали, что МСМЧК, синтезированные с добавлением АПТЭС в реакционную смесь и отожженные на воздухе при $550^{\circ} \mathrm{C}$, имеют большой объем пор $\left(0.36 \mathrm{~cm}^{3} / \mathrm{g}\right)$. По-видимому, при температуре $550^{\circ} \mathrm{C}$ массоперенос газообразных продуктов терморазложения АПТЭС из пор МСМЧК наружу отсутствует (разложение завершено), и образовавшиеся при $250^{\circ} \mathrm{C}$ углеродные наноточки окисляются кислородом, диффундирующим по поверхности мезопор внутрь МСМЧК.

На ПЭМ-изображении частиц кремнезема, содержащих в порах УНТ (рис. 2,a), видно, что МСМЧК после заполнения сохраняют сферическую форму и монодисперсность. Массивный углеродный материал отсутствует на поверхности частиц темплата и в пространстве между ними. Вероятно, АПТЭС полностью переходит из раствора в поры частиц, и твердофазные продукты его терморазложения тоже остаются внутри МСМЧК. После растворения материала МСМЧК (аморфного $\mathrm{SiO}_{2}$ ) в растворе остаются квазисферические наночастицы размером $\sim 3 \mathrm{~nm}$ (темные области на рис. $2, b)$. На полученных изображениях ПЭМ с высоким разрешением (ПЭМВР) видно, что наночастицы являются кристаллическими и не имеют выраженного направления ориентации. Наблюдаемое на приведенной на рис. 2, с ПЭМВР-микрофотографии периодическое расположение полос на расстоянии $0.34 \mathrm{~nm}$ друг от друга отвечает межплоскостному расстоянию в графите $d_{002}=0.3354 \mathrm{~nm}$. Таким образом, результаты ПЭМВР-исследований подтверждают, что наблюдаемые наночастицы состоят из углерода.

На рис. 3 показана спектральная зависимость оптической плотности коллоидного раствора УНТ до (кривая 1) и после (кривая 2) центрифугирования при ускорении $15000 \mathrm{~g}$ в течение $1 \mathrm{~h}$. Наблюдаемый вид спектральных зависимостей оптической плотности обусловлен поглощением УНТ в ультрафиолетовой области спектра и рэлеевским рассеянием света $[1,7]$. Видно, что кривые 1 и 2 различаются только в длинноволновой спектральной области $(500-700 \mathrm{~nm})$. Это небольшое различие (коэффициент пропускания при $600 \mathrm{~nm}$ различается на $\sim 2 \%$ ), по-видимому, вызвано осаждением при центрифугировании агрегатов углеродных наноточек, имеющих по данным ДСР и ПЭМ размер в десяткисотни нанометров. Поскольку интенсивность рассеянного света пропорциональна шестой степени гидродинамического диаметра частиц, а оптическая плотность

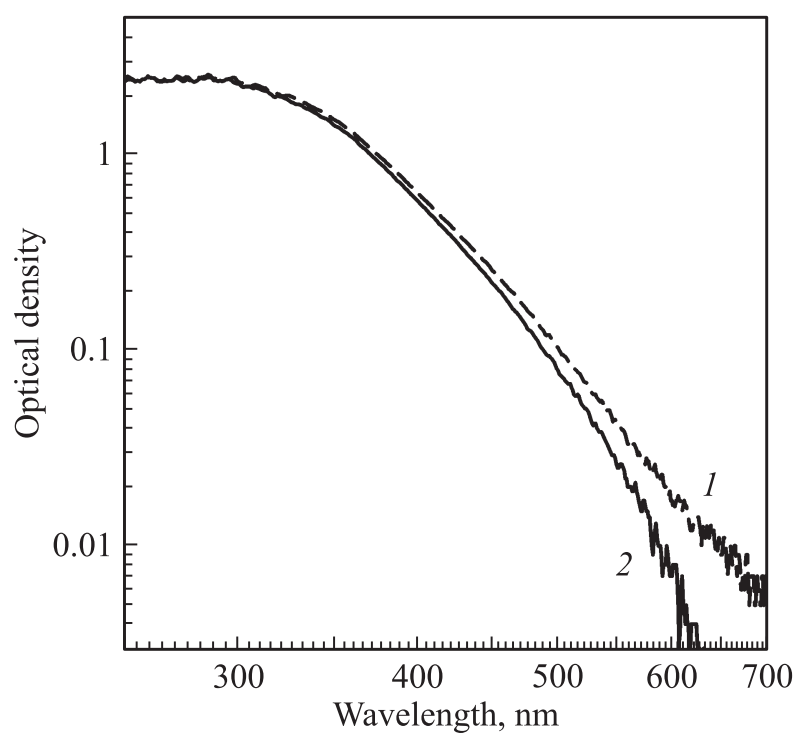

Рис. 3. Оптическая плотность коллоидного раствора УНТ до (1) и после (2) центрифугирования при ускорении $15000 \mathrm{~g}$. 


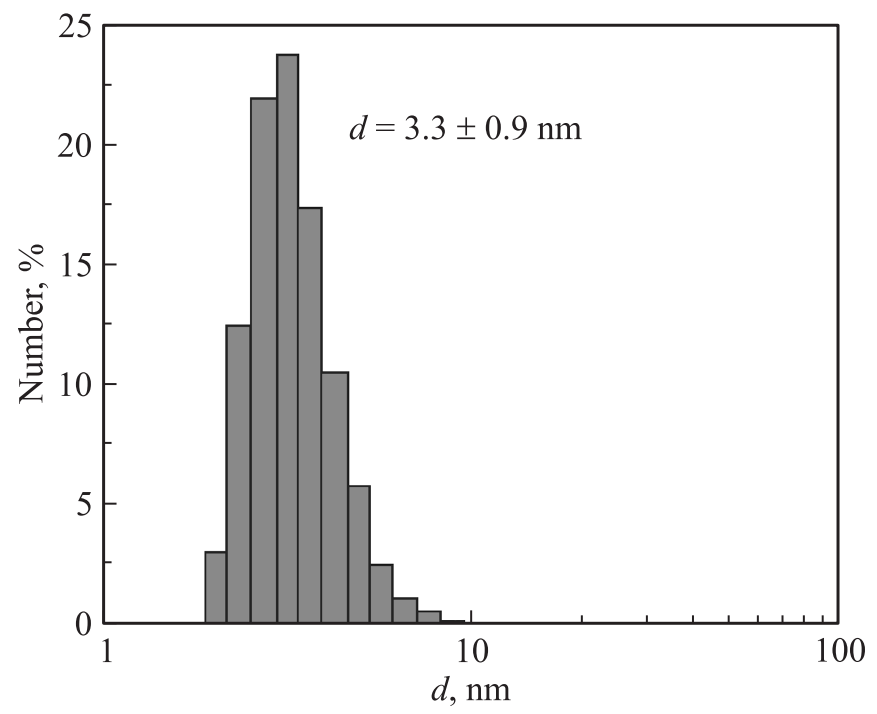

Рис. 4. Распределение гидродинамических диаметров УНТ в коллоидном растворе, измеренное методом ДСР.

после центрифугирования изменяется не сильно, можно заключить, что количество агрегатов невелико. Средний диаметр УНТ после очистки центрифугированием составил $3.3 \pm 0.9 \mathrm{~nm}$ (рис. 4).

Фотолюминесценция полученных УНТ, находящихся как в порах МСМЧК, так и в коллоидном растворе, детально исследована в работе [33]. Показано, что коллоидный раствор УНТ интенсивно люминесцирует в ультрафиолетовой и видимой областях спектра. Положение максимума, форма спектра и интенсивность фотолюминесценции сильно зависят от длины волны возбуждающего излучения и температуры [33].

Таким образом, разработан метод темплатного синтеза монодисперсных углеродных наноточек, включающий заполнение пор субмикронных монодисперсных сферических мезопористых частиц кремнезема спиртовым раствором аминопропилтриэтоксисилана, его термическое разложение при $250^{\circ} \mathrm{C}$ и селективное травление кремнеземного темплата водным раствором НF. Полученный коллоидный раствор УНТ исследован методами ПЭМ, ДСР и спектроскопии пропускания. Показано, что разработанная методика позволяет синтезировать УНТ размером $3.3 \pm 0.9 \mathrm{~nm}$ (согласно ДСР). Углеродные наночастицы по данным ПЭМ являются кристаллическими, имеют графитоподобную структуру и близкую к сферической форму.

Разработанный метод получения не требует длительных и дорогостоящих процедур очистки. При синтезе УНТ загрязнения минимальны, поскольку используются раствор однокомпонентного кремнийорганического прекурсора в органическом растворителе и однокомпонентный водный раствор травителя. Благодаря высокому массовому содержанию углерода в АПТЭС (49wt.\%) и реализации близкого к полному заполнения пор МСМЧК прекурсором метод позволил достичь большого выхода конечного продукта, который составил $100 \mathrm{mg}$ УНТ на $1 \mathrm{~g}$ темплата.

\section{Список литературы}

[1] S.N. Baker, G.A. Baker. Angew. Chem. Int. Ed. 49, 6726 (2010).

[2] H. Li, Z. Kang, Y. Liu, S.-T. Lee. J. Mater. Chem. 22, 24230 (2012).

[3] J. Shen, Y. Zhu, X. Yang, C. Li. Chem. Commun. 48, 3686 (2012).

[4] C.J. Reckmeier, J. Schneider, A.S. Susha, A.L. Rogach. Opt. Express 24, A312 (2015).

[5] P. Gopinath, S.U. Kumar, I. Matai, B. Bhushan, D. Malwal, A. Sachdev, P. Dubey. Cancer nanotheranostics. SpringerVerlag (2015). 119 p.

[6] Q. He, M. Ma, C. Wei, J. Shi. Biomaterials 33, 4392 (2012).

[7] S.K. Bhunia, A. Saha, A.R. Maity, S.C. Ray, N.R. Jana. Sci. Rep. 3, 1473 (2013).

[8] W. Kwon, S. Do, J.-H. Kim, M.S. Jeong, S.-W. Rhee. Sci. Rep. 5, 12604 (2015).

[9] J. Zuo, T. Jiang, X. Zhao, X. Xiong, S. Xiao, Z. Zhu. J. Nanomat. 2015, 787862 (2015).

[10] H. Xu, X. Yang, G. Li, C. Zhao, X. Liao. J. Agric. Food Chem. 63, 6707 (2015).

[11] P. Serp, B. Machado. Nanostructured carbon materials for catalysis. Royal Society of Chemistry (2015). 570 p.

[12] S. Sahu, B. Behera, T.K. Maiti, S. Mohapatra. Chem. Commun. 48, 8835 (2012).

[13] S.Y. Park, H.U. Lee, E.S. Park, S.C. Lee, J.-W. Lee, S.W. Jeong, C.H. Kim, Y.-C. Lee, Y.S. Huh, J. Lee. ACS Appl. Mater. Interfaces 6, 3365 (2014).

[14] R.L. Liu, D.Q. Wu, S.H. Liu, K. Koynov, W. Knoll, Q. Li. Angew. Chem. Int. Ed. 48, 4598 (2009).

[15] A.B. Bourlinos, A. Stassinopoulos, D. Anglos, R. Zboril, V. Georgakilas, E.P. Giannelis. Chem. Mater. 20, 4539 (2008).

[16] J. Zong, Y. Zhu, X. Yang, J. Shen, C. Li. Chem. Commun. 47, 764 (2011).

[17] Е.Ю. Трофимова, Д.А. Курдюков, Ю.А. Кукушкина, М.А. Яговкина, В.Г. Голубев. ФХС 37, 38 (2011).

[18] E.Yu. Trofimova, D.A. Kurdyukov, S.A. Yakovlev, D.A. Kirilenko, Yu.A. Kukushkina, A.V. Nashchekin, A.A. Sitnikova, M.A. Yagovkina, V.G. Golubev. Nanotechnology 24, 155601 (2013).

[19] D.A. Kurdyukov, D.A. Eurov, D.A. Kirilenko, J.A. Kukushkina, V.V. Sokolov, M.A. Yagovkina, V.G. Golubev. Micropor. Mesopor. Mater. 223, 225 (2016).

[20] D.A. Eurov, D.A. Kurdyukov, D.A. Kirilenko, J.A. Kukushkina, A.V. Nashchekin, A.N. Smirnov, V.G. Golubev. J. Nanopart. Res. 17, 82 (2015).

[21] K.N. Orekhova, D.A. Eurov, D.A. Kurdyukov, V.G. Golubev, D.A. Kirilenko, V.A. Kravets, M.V. Zamoryanskaya. J. Alloy Compd. 678, 434 (2016).

[22] Д.А. Курдюков, Д.А. Еуров, Е.Ю. Стовпяга, С.А. Яковлев, Д.А. Кириленко, В.Г. Голубев. ФТТ 56, 995 (2014).

[23] D.A. Eurov, D.A. Kurdyukov, E.Yu. Stovpiaga, A.S. Salasyuk, J. Jäger, A.V. Scherbakov, A.V. Akimov, A.J. Kent, D.R. Yakovlev, M. Bayer, V.G. Golubev. J. Phys. D 47, 335303 (2014).

[24] F. Wang, Z. Xie, H. Zhang, C. Liu, Y. Zhang. Adv. Funct. Mater. 21, 1027 (2011). 
[25] Z. Xie, F. Wang, C. Liu. Adv. Mater. 24, 1716 (2012).

[26] Е.Ю. Трофимова, С.А. Грудинкин, Ю.А. Кукушкина, Д.А. Курдюков, А.В. Медведев, М.А. Яговкина, В.Г. Голубев. ФТТ 54, 1220 (2012).

[27] Д.А. Еуров, С.А. Грудинкин, Д.А. Курдюков, А.В. Медведев, Е.Ю. Стовпяга, В.Г. Голубев. Письма в ЖТФ 41, 19, 1 (2015).

[28] F.A.L. Dullien. Porous media fluid transport and pore structure. 2nd ed. Academic Press Inc. (1992). 574 p.

[29] E.R. Gilliland, R.F. Baddour, J.L. Russell. AIChE Journal 4, 90 (1958)

[30] M.G.M. Van der Vis, E.H.P. Cordfunke, R.J.M. Konings. J. Phys. IV (France) 3, C 3-75 (1993).

[31] V.V. Semenov, L.G. Klapshina, W.E. Douglas, G.A. Domrachev. Mendeleev Commun. 10, 157 (2000).

[32] C.P. Jaroniec, R.K. Gilpin, M. Jaroniec. J. Phys. Chem. B 101, 6861 (1997).

[33] D.K. Nelson, B.S. Razbirin, A.N. Starukhin, D.A. Eurov, D.A. Kurdyukov, E.Yu. Stovpiaga, V.G. Golubev. Opt. Mater., 59, 28 (2016). 